\title{
RECOMPENSAR SERVICIOS CON HONORES: EL CRECI- MIENTO DE LA NOBLEZA TITULADA EN LOS REINADOS DE FELIPE IV Y CARLOS II"
}

\section{To Reward Services with Honors: the Growth of the Nobility Titled in the Reigns of Philip IV and Charles II}

\author{
María del Mar FELICES DE LA FUENTE \\ Universidad de Almería \\ Correo-e: fdm072@ual.es
}

RESUMEN: En el transcurso del siglo XVII, la nobleza titulada dejó de ser un grupo selecto y restringido para ir abriéndose paulatinamente a nuevos miembros que, incluso sin contar con un origen noble, lograron alcanzar un título nobiliario a través de las múltiples vías que fueron estableciéndose para ello. A pesar de la escasez de trabajos monográficos relativos a la concesión de estos honores durante este siglo, todo apunta a que hasta el reinado de Felipe IV recayeron fundamentalmente en primogénitos y segundones de las principales Casas nobiliarias. Sin embargo, desde entonces y sobre todo en tiempos de Carlos II, la política de creación de títulos nobiliarios varió de forma significativa no ya solo por el espectacular incremento que experimentaron, sino también porque en buena parte fueron otorgados a quienes acreditaban como principal mérito un desembolso económico. En el presente trabajo, a partir de los estudios existentes y la consulta de fuentes documentales inéditas, se analizan, entre otros aspectos, el cambio que experimentó la cima del estamento privilegiado durante este periodo, los méritos que fueron recompensados con tan preciadas mercedes, y la naturaleza de las nuevas elites que lograron titular, pues amén de la existencia de

El presente estudio se ha realizado en el marco del Proyecto de Investigación de I+D El poder del dinero. Dimensiones de la venalidad en los siglos XVII y XVIII (HAR2011-23105), financiado por el Ministerio de Economía y Competitividad. 
agraciados que respondían plenamente al concepto tradicional de nobleza, también hubo títulos nobiliarios que fueron a parar a manos de personas que, con orígenes oscuros o inciertos, habían servido únicamente a la Corona con el «mérito» del dinero.

Palabras clave: Felipe IV, Carlos II, siglo XVII, estamento nobiliario, nobleza titulada, inflación de honores, venalidad.

ABSTRACT: During the seventeenth century, the nobility titled ceased to be a select and limited group for to open up gradually to new members, even without a noble origin, who were able to achieve a nobility title trough diverses systems that were established for it. Although there are few studies about the creation of these honors during this century, it seems that until the reign of Philip IV, the nobility titles were granted mainly to firstborns and younger sons of the main noble Houses. However, since then and especially in the reign of Charles II, the policy of creating nobility titles varied significantly by the large increase they experienced, and because in large part they were awarded to whom offered the money as the main merit. In this study, based on existing studies and consultation of unpublished documents, we analyze, among other things, the change that the top of the privileged class experienced during this period, the merits that were rewarded with grants so precious, and the new elites who managed to get this honors. Although there were new graduates who responded to the traditional concept of nobility, there were also nobility titles that were granted to people with dark or uncertain origins, who had served to the Crown only with the «merit» of money.

Key words: Philip IV, Charles I, Seventeenth century, Nobility estate, Nobility titled, Inflation of honors, Venality.

1. El CRecimiento del grupo. De cifras y formas de acceso a la nobleza TITULADA

Desde las primeras décadas del siglo xviI hubo un cambio significativo en el estamento nobiliario y sobre todo en su cota más alta, la nobleza titulada, pues lo que antaño había sido un grupo social fundamentado en la sangre y en la guerra, fue apartándose de sus funciones militares y de sus lugares de origen para asentarse en la Corte en torno al servicio real ${ }^{1}$. Asimismo, este reducido grupo iría ampliándose

1. Un ejemplo significativo de la pérdida de vocación militar que manifestaba la nobleza lo tenemos en lo ocurrido en 1640, cuando la mayor parte del estamento nobiliario, ante el llamamiento del Conde Duque de Olivares para combatir contra los ejércitos franceses, rehuyó de sus obligaciones. 
paulatinamente con el ingreso en sus filas de nuevos titulados que, lejos de haber servido en la guerra y de responder a los viejos ideales de nobleza caballeresca, lograron alcanzar un título nobiliario a través de múltiples vías. Fue en tiempos de Felipe IV cuando comenzó a experimentar un leve crecimiento el número de nobles titulados, si bien iba a ser durante el reinado de su sucesor cuando la concesión de títulos se aceleró de manera sustancial, en un proceso conocido como de inflación de honores que estuvo estrechamente vinculado a una gran almoneda que alcanzó también a los cargos y oficios ${ }^{2}$. Muchos de los nuevos titulados, sobre todo ya a finales de siglo, carecieron incluso de un origen noble, no obstante, la continua renovación de la cota más alta del estamento nobiliario a través de la incorporación de nuevos miembros, lejos de perjudicar el orden establecido, vendría a reforzarlo aún más y a mantener su continuidad mediante el aporte de riqueza y poder al conjunto 3 .

Durante el reinado de Felipe IV, la nobleza titulada, en comparación con etapas anteriores, aumentó ya de forma notable $e^{4}$ debido sobre todo al intento del Conde

Vid. Domínguez OrTiz, A.: «La movilización de la nobleza castellana en 1640», Anuario de Historia del Derecho Español, 25 (1955), pp. 799-823; además, ConTreras GAY, J.: «El servicio Militar en España durante el siglo XVII», Chronica Nova, 21, (1993-1994), pp. 99-122. Aún así, recientemente se han puesto de manifiesto planteamientos contrapuestos que argumentan que hubo algunos sectores de la nobleza que sí estuvieron dispuestos a servir, aunque en defensa de sus propios territorios y no de la monarquía. Véanse al respecto los trabajos de Hernández Franco, J. y Molina Puche, S.: «El retraimiento militar de la nobleza castellana con motivo de la guerra franco-española (16351648). El ejemplo contrapuesto del reino de Murcia», Cuadernos de Historia Moderna, 29 (2004), pp. 111-130; o para el caso de Jérez de la Frontera el de Jiménez Moreno, A.: «Poder central y poderes locales. El cumplimiento de la convocatoria de los caballeros de hábito del año 1640 en Jérez de la Frontera» en BRavo Caro, J. J. y Villas Tinoco, S. (eds.): Tradición versus innovación en la España Moderna. Málaga, 2009, vol. II, pp. 705-728.

2. Para un conocimiento más exhaustivo sobre el tema puede consultarse la bibliografía incluida en Marcos Martín, A.: «Enajenaciones por precio del patrimonio regio en los siglos XVI y XVII. Balance historiográfico y perspectiva de análisis», en Balance de la historiografía modernista, 19732001. Actas del VI coloquio de Metodología Histórica Aplicada (Homenaje al Profesor Antonio Eiras Roel). Santiago de Compostela, 2003, pp. 419-443. Asimismo, remitimos a la bibliografía contenida en el monográfico que la revista Chronica Nova dedicó hace unos años a estos aspectos: Venalidad de cargos y honores en la España Moderna, 33 (2007); y a la que se incluye en algunas de las monografías más recientes al respecto: SANZ TAPIA, Á.: ¿Corrupción o necesidad? La venta de cargos de gobierno americanos bajo Carlos II (1674-1700). Madrid, Consejo Superior de Investigaciones Científicas, 2009; o Andújar Castillo, F. y Felices de la Fuente, M. M. (eds.): El poder del dinero. Venta de cargos y honores en la España del Antiguo Régimen. Madrid, Biblioteca Nueva, 2011.

3. Soria Mesa, E.: La nobleza en la España Moderna. Cambio y continuidad. Madrid, 2007, p. 16.

4. Véanse al respecto las cifras aportadas por Soria Mesa, E.: La nobleza en la España Moderna..., op. cit., p. 51. Hacia 1627, según una nómina elaborada por el Consejo de Hacienda, en Castilla había unos 168 títulos, los cuales se desglosaban en veinticinco duques, todos ellos Grandes de España; setenta marqueses, nueve de ellos Grandes; y setenta y tres condes, de los cuales siete también disfrutaban de la categoría de Grandes. Cfr. ElliotT, J. H.: El conde-duque de Olivares. El político en una época de decadencia. Barcelona, 2005, p. 196. 
Duque de Olivares de crear una nobleza «comprometida y dispuesta a sacrificarse en aras del bien de la "república" ${ }^{5}$. Según Olivares, era necesario configurar una verdadera nobleza administrativa, ya que los nobles e hidalgos de Castilla habían perdido su vocación militar y se habían convertido en un grupo de ociosos y decadentes ${ }^{6}$. El incremento de la nobleza titulada también se vio favorecido por la confrontación existente entre el valido de Felipe IV y una alta nobleza que no estaba dispuesta a seguir los dictados de alguien que la había desplazado de su posición privilegiada ${ }^{7}$. Por ello, ante la falta de apoyos, el Conde Duque trató de forjar una nueva nobleza basada en el mérito y el servicio - de cuya actividad, influencia y dinero se beneficiaría la monarquía- que sería recompensada con toda clase de distinciones siempre y cuando cumpliera con sus obligaciones ${ }^{8}$. No obstante, junto a este proyecto de crear una nobleza de servicio, también pervivió la tradición de conceder títulos nobiliarios a individuos pertenecientes a Casas ya distinguidas con las dignidades de condes, marqueses, duques o Grandes de

5. Jiménez Moreno, A.: «En busca de una nobleza de servicio. El Conde Duque de Olivares, la aristocracia y las Órdenes Militares (1621-1643)» en Rivero Rodríguez, M. (coord.): Nobleza Hispana, Nobleza Cristiana: la Orden de San Juan. Madrid, 2009, vol. I, p. 212.

6. Fue entonces cuando Olivares propuso, en 1625, la concesión de honores a hombres que hubieran servido al rey en sus ejércitos o armadas, o que hubieran dedicado sus vidas al comercio. Su planteamiento implicaba, además, que los servicios militares o mercantiles pudieran eliminar cualquier «mancha de raza», dando así acceso directo a los títulos de nobleza a todo aquel que lo mereciera, cuestión que fue rechazada por diversas juntas de ministros, por el Consejo de Estado y la Cámara de Castilla, que advirtieron al rey de las serias consecuencias que podrían seguirse de otorgar cartas de nobleza y limpieza de sangre a quienes no las poseyeran. $C f r$. ElliotT, J. H., El conde-duque de Olivares..., op. cit., pp. 199 y 303. Sobre la formulación de Olivares acerca de la nobleza y algunos de sus intentos de reforma, vid. Borrego Pérez, M.: «La crítica de una nobleza irresponsable. Un aspecto de los memoriales del Conde Duque», Criticón, 56 (1992), pp. 87-101. Interesa además el reciente trabajo de Carrasco Martínez, A.: «Le conflit idéologique et politique entre la tradition de l'honneur nobiliaire et les réformes d'Olivarès» en Drévillon, H. y Venturino, D. (dirs.): Penser et vivre l'honneur à l'époque moderne. Actes du colloque organisé a Metz par le CRULH (Centre Regional Universitaire Lorrain d'Histoire) du 20 an 22 novembre 2008. Rennes, 2011, pp. 43-56.

7. Sobre la oposición de la aristocracia a la política del Conde Duque de Olivares, vid. entre otros, JAGO, C. J.: «La Corona y la aristocracia durante el régimen de Olivares: un representante de la aristocracia en la Corte», en Elliott, J. H. y García SANZ, Á. (coords.): La España del Conde Duque de Olivares. Valladolid, 1990, pp. 373-398; ElliotT, J. H., El conde-duque de Olivares..., op. cit., pp. 129 et passim.

8. La apertura del estamento nobiliario propiciada por Olivares -fundamentada en numerosas provisiones de hábitos de las Órdenes Militares y títulos nobiliarios-implicó la necesidad de debilitar la importancia de la sangre como factor de honra y distinción social, por lo que el proyecto del Conde Duque se encontró con la oposición de las instituciones más conservadoras como la Inquisición y los colegios Mayores, quienes pensaban que abrir las puertas de la nobleza podría «desdorar las instituciones nobiliarias». Véase al respecto GutiérRez NiETO, J. I.: «El reformismo social de Olivares: el problema de la limpieza de sangre y la creación de una nobleza de mérito» en ELLiotT, J. H. y García SAnZ, Á. (coords.): La España del Conde Duque de Olivares. Valladolid, 1990, pp. 419-441. 
España. Por otro lado, parte de estos nuevos títulos irían a parar a las clientelas y parentelas de Olivares, las cuales se vieron altamente favorecidas con todo tipo de cargos, honores y nombramientos. Tal fue el caso de las Casas de Guzmán, Haro, Zúñiga, Fonseca y Pimentel, con las cuales estaba emparentado el Conde Duque?.

Es preciso señalar además que entre las medidas impulsadas por el valido estuvo la de exigir el pago de lanzas y medias annatas a aquellos que habían sido agraciados con un título nobiliario. Así, por decreto de 22 de mayo de $1631^{10}$ y posteriores Cédulas de 18 de agosto de 1631 y 10 de diciembre de $1632^{11}$, Felipe IV hizo efectivas estas cargas en un contexto de fiscalidad de guerra en el que era necesario obtener medios con que financiar las necesidades de la Monarquía Hispánica. Igualmente, por Reales Cédulas de 15 de octubre de 1631 y 3 de julio de 1644, se dispuso que en lo sucesivo no se otorgaran títulos de marqueses o condes sin que precediera el de vizconde, que quedaría cancelado al otorgarse aquellos. Esta medida tuvo nuevamente un carácter fiscal, por cuanto el interesado debía pagar lo correspondiente a la media annata no solo por el título de conde o marqués, sino también por el de vizconde ${ }^{12}$. En algunos casos, los agraciados con títulos nobiliarios carecieron de recursos para hacer frente al pago de estos derechos, por lo que los títulos nobiliarios o bien no llegaron a expedirse, o acumularon una deuda tal -sobre todo por el impago de lanzas- que fue preciso que sus titulares pidieran moratorias al rey para cumplir con este impuesto.

En relación al número de títulos que se crearon a lo largo del reinado de Felipe IV, los datos aportados por Domínguez Ortiz, basados únicamente en las fuentes del Archivo Histórico Nacional, ascienden a 67 marquesados y 25 condados $^{13}$, cifras que contrastan bastante con las que presenta Enrique Soria Mesa, que establece en 329 los títulos nobiliarios otorgados por este monarca ${ }^{14}$. Entre ambas cantidades se situarían las aportadas por Antonio José Rodríguez Hernández, quien a partir de los Libros de Relación de la Cámara de Castilla constató la creación de

9. Elliott, J. H., El conde-duque de Olivares..., op. cit., pp. 153-156.

10. Cfr. Rodríguez Vicente, M. E.: «El derecho de la media annata» en Poder y presión fiscal en la América española: siglos XVI, XVII y XVIII. Valladolid, 1986, p. 485. Sobre el derecho de la media annata véase además el trabajo de SANz Ayán, C.: «El canón a la nobleza en la Monarquía Hispánica: la media annata de mercedes» en Marcos Martín, A. (ed.): Hacer historia desde Simancas. Homenaje a José Luis Rodríguez de Diego. Valladolid, 2011, pp. 705-726.

11. Cfr. Mayoralgo y Lodo, J. M. de (conde de los Acevedos): Historia y régimen jurídico de los títulos nobiliarios. Madrid, 2007, p. 186. Sobre el derecho de la media annata y el servicio de lanzas, véase la obra de Rezábal y UGARTE, J. de: Tratado del Real derecho de las medias annatas seculares y del servicio de lanzas al que están obligados los Títulos de Castilla. Madrid, 1792.

12. Cfr. Mayoralgo y Lodo, J. M. de (conde de los Acevedos): Historia y régimen jurídico..., op. cit., p. 80.

13. Domínguez Ortiz, A.: La sociedad española en el siglo XVII. Granada, 1992, vol. I, p. 210.

14. Soria Mesa, E.: La nobleza en la España Moderna..., op. cit., p. 51. 
71 títulos de marqueses, 53 de condes y 2 de duques, además de 21 vizcondados, de los cuales 9 pasarían más tarde a convertirse en condados y marquesados ${ }^{15}$.

Con Carlos II la cifra de nobles titulados siguió en ascenso. Según Domínguez Ortiz se concedieron 209 marquesados, 78 condados y 5 vizcondados ${ }^{16}$, mientras que los datos aportados por Henry Kamen -obtenidos a partir de las fuentes del Archivo Histórico Nacional y otros catálogos y fuentes impresas- elevaban las creaciones hasta 236 marquesados, 80 condados y 12 vizcondados ${ }^{17}$. Similares a estas últimas son las cantidades que señaló Antonio José Rodríguez, cifradas en 212 marquesados, 84 condados y 16 vizcondados ${ }^{18}$. Por encima de ellas $-\mathrm{y}$ más acorde con nuestras estimaciones- están las aportadas por Enrique Soria Mesa, quien establece en al menos 411 los títulos nobiliarios otorgados durante este reinado ${ }^{19}$.

De los datos expuestos llaman la atención dos cuestiones. En primer lugar, el gran aumento que experimentó la nobleza titulada durante el siglo xviI, pues de aproximadamente 307 títulos nobiliarios que existían a finales del reinado de Felipe III, la cifra se elevó como mínimo a 1.047 títulos a la altura de $1700^{20}$. En segundo lugar, destaca la gran disparidad que existe entre las cifras aportadas por los diversos autores, cuestión que responde a los criterios de contabilización -ya que no es lo mismo incluir en el recuento solo los títulos de Castilla, que añadir además los de Navarra, Aragón e Italia, o los tramitados por la Cámara de Indias-y al hecho, como bien expone Enrique Soria, de que algunos títulos tuvieron corta vida, bien porque fueron concedidos con carácter vitalicio y desaparecieron al fallecer sus titulares, porque no fueron sacados los despachos correspondientes, porque no tuvieron sucesor, e incluso porque algunos de estos honores fueron tomados ilícitamente por sus titulares, nominándose como condes o marqueses sin derecho alguno ${ }^{21}$.

El problema radica igualmente en las fuentes documentales manejadas para contabilizar el conjunto de títulos nobiliarios concedidos, pues no todas registraron las mismas provisiones o el total de ellas, como es el caso de los Libros de Relación de la Cámara de Castilla, en los que solo se incluían los títulos concedidos en Castilla y Navarra, excluyéndose así el resto de títulos provistos ${ }^{22}$. En

15. Rodríguez Hernández, A. J.: «La creación de Títulos de Castilla durante los reinados de Felipe IV y Carlos II: concesiones y ritmos» en Díaz LóPEz, J. P., ANDÚJAR Castillo, F. y Galán Sánchez, Á. (eds.): Casas, Familias y Rentas. La nobleza del Reino de Granada entre los siglos XV-XVIII. Granada, 2010, pp. 168-169.

16. Domínguez Ortiz, A.: La Sociedad Española..., op. cit., p. 210.

17. Kamen, H.: La España de Carlos II. Barcelona, 1981, p. 411.

18. Rodríguez Hernández, A. J.: «La creación de Títulos de Castilla...», art. cit., p. 182.

19. Soria Mesa, E.: La nobleza en la España Moderna..., op. cit., p. 50.

20. Ibidem, p. 51.

21. Ibidem, p. 50.

22. Rodríguez Hernández, A. J.: «La creación de Títulos de Castilla...», art. cit., p. 169. 
los registros de la Cámara de Castilla no quedó constancia, por tanto, de los títulos dados por el Consejo de Italia, o de los títulos concedidos en Indias y expedidos por la Cámara de Indias. En el caso concreto de los títulos nobiliarios otorgados en América fue su Cámara la encargada de despachar y anotar estas mercedes, circunstancia que llegó a provocar incluso las protestas de la Cámara de Castilla, que vio como una pérdida de poder y competencias el hecho de que se estuvieran despachando - por la Cámara de Indias- títulos de Castilla en aquellos territorios sin ser informada de ello ${ }^{23}$.

Con los nuevos títulos nobiliarios ambos monarcas, Felipe IV y Carlos II, vinieron a recompensar servicios de diversa índole -entre otros, políticos, cortesanos, militares, administrativos o pecuniarios-, conformándose así una nueva nobleza que siempre estaría dispuesta a continuar asistiendo al rey para ser premiada con sucesivas mercedes ${ }^{24}$. Evidentemente, el crecimiento espectacular que experimentó la nobleza titulada a lo largo del siglo xvi supuso un cambio significativo en su seno, pues lo que había sido un grupo relativamente cerrado y reducido comenzó a integrar en sus filas a personas de diversa procedencia social. Durante el reinado de Felipe III estas dignidades nobiliarias habían recaído principalmente en individuos pertenecientes a familias ya tituladas ${ }^{25}$, y por tanto, eran los segundones de las principales Casas nobiliarias o de ramas colaterales de la alta nobleza los que se veían agraciados con aquellas distinciones, siendo esta vía, junto a la del matrimonio, la que dio lugar a la concentración de diversos

23. Así lo hizo constar ante la pretensión de que se le guardaran «los honores y privilegios» de título de Castilla a Luis Antonio de Oviedo, conde de la Granja, cuyo título había sido despachado por la Cámara de Indias tras ser comprado al duque de la Palata, virrey de Perú. Archivo General de Indias [en adelante AGI], Indiferente General, leg. 496, lib. 50, fols. 61 v-62 r; información al respecto también en AGI, Lima, leg. 12.

24. Durante el Antiguo Régimen funcionó lo que Antonio Manuel Espanha denominó «economía de la gracia», o lo que más recientemente ha definido Fernanda Olival como «economía de la merced», un sistema de intercambio de servicios por mercedes que estructuró las relaciones políticas entre reyes y súbditos a lo largo de la Edad Moderna, de tal modo que ambas partes tenían la obligación de hacerse prestaciones mutuas manteniendo así la cohesión social. Vid. Hespanha, A. M.: La gracia del derecho. Economía de la cultura en la Edad Moderna. Madrid, 1993, pp. 151-176; Olival, F.: «La economía de la merced en la cultura política del Portugal moderno» en Aranda Pérez, F. J. y Rodrigues, J. D. (eds.): De Re Publica Hispaniae. Una reivindicación de la cultura política en los reinos ibéricos en la primera modernidad. Madrid, 2008, pp. 389-407; Bravo Lozano, J.: «Gracia y merced en época de desgracias. Cámara y vida cotidiana en el reinado de Carlos II», en Bravo Lozano, J. (ed.): Espacios de poder: Cortes, Ciudades y Villas (s. XVI - XVIII). Madrid, 2002, pp. 101-121; De Dios, S.: «El ejercicio de la gracia regia en Castilla entre 1250 y 1530. Los inicios del Consejo de la Cámara», Anuario de historia del derecho español, 60 (1990), pp. 323-352.

25. Sobre los títulos nobiliarios creados en el reinado de Felipe III, véase, entre otros, el trabajo de Martínez Hernández, S.: «Los cortesanos. Grandes y títulos frente al régimen de validos» en Martínez Millán, J. y Visceglia, M. A. (dirs.): La monarquía de Felipe III: La Corte. Madrid, 2008, vol. III, pp. 466-524. 
títulos nobiliarios en una misma persona o Casa. Este sistema de concesión, que implicó un refuerzo del estamento nobiliario y un aislamiento de posibles «elementos» extraños o advenedizos, se mantuvo todavía durante el reinado de Felipe IV, cuando se titularon diversos miembros de las familias más relevantes de la nobleza española-incluyendo en ellas tanto Casas del más rancio abolengo como Casas de origen más reciente-, atendiendo seguramente a un intento por parte de Olivares de atraerse y fidelizar a las principales Casas nobles, sobre todo a las que servían en cargos palatinos.

A partir del reinado de Carlos II, de forma gradual, los títulos dejaron de otorgarse a miembros de las principales Casas nobiliarias y pasaron a ser concedidos en mayor medida a aquellos individuos que habían ofrecido sus servicios al rey, lo que implicó un aumento considerable de los nobles titulados y una ruptura del hermetismo en que había vivido el sector más tradicional de la aristocracia. En cuanto al ritmo de creación de nuevos títulos durante la primera etapa del reinado, parece que fue algo bajo, estableciéndose en cifras similares a las que se habían registrado con Felipe IV $^{26}$. Sin embargo, esa dinámica no tardaría en cambiar, pues a partir de 1679 , con motivo del casamiento real entre Carlos II y Mariana Luisa de Orleans, se produjo un notable giro en la política de concesión de títulos, iniciándose una verdadera inflación de bonores -producto de la enajenación masiva de estas mercedes- que perduraría hasta finales del siglo xviI. Ante la imposibilidad de la Real Hacienda de hacer frente a los fastos del enlace, afectada por un gran déficit fruto de los continuos gastos generados por la guerra, se acometió una enorme operación venal que incluyó la venta de al menos 35 títulos nobiliarios ${ }^{27}$, algunos de los cuales fueron a parar a individuos de dudoso origen, cuyo único mérito esgrimido había sido el dinero ${ }^{28}$. A tal efecto, la enajenación

26. Vid. Rodríguez Hernández, A. J.: «La creación de Títulos de Castilla...», art. cit., pp. 180-181.

27. Cfr. en Andújar Castillo, F.: «Hacerse noble a finales del siglo XviI. Las contradicciones de la jerarquía nobiliaria» en Jiménez Estrella, A., Lozano Navarro, J. J., Sánchez-Montes González, F. y Birriel Salcedo, M. M. (eds.), Construyendo historia. Estudios en torno a Juan Luis Castellano. Granada, 2013, pp. 18-19. Uno de los títulos nobiliarios adquiridos entonces fue el de marqués de Santa Cruz de Marcenado que recayó en Sebastián Vigil de Quiñones y de la Rúa. Acerca del linaje asturiano de los Vigil de Quiñones, el estudio de Juan Díaz Álvarez, que muestra el proceso de ascenso de la familia y las estrategias que emplearon para perpetuarse en el poder municipal, nada dice al respecto de la forma de acceso a un título que fue obtenido por un servicio pecuniario de 38.000 ducados. Vid. Díaz Álvarez, J.: Ascenso de una Casa asturiana: los Vigil de Quiñones, marqueses de Santa Cruz de Marcenado. Oviedo, Real Instituto de Estudios Asturianos, 2006.

28. Es el caso, entre otros, de Francisco Chacón Enríquez, quien tituló como conde de Mollina tras desembolsar 30.000 ducados, a pesar de que uno de sus antepasados era el malagueño Diego de Cazalla, un descendiente de conversos que merced a su actividad económica logró enriquecerse y promocionar socialmente. Sobre Diego de Cazalla véase Alfonso SAntorio, P.: «El pagador de armadas Diego de Cazalla, origen de un condado malagueño» en Díaz López, J. P., Andújar 
de estos honores se hizo a través de una Junta Particular de Medios creada ex novo con el fin de recaudar dinero con que asistir al rey y pagar los gastos de la Corte $^{29}$. Esta operación tuvo su principal foco de clientes en Sevilla, donde fueron numerosos los individuos que, enriquecidos fundamentalmente con el comercio y otras actividades lucrativas, vieron en esta oportunidad una coyuntura idónea para acceder a la nobleza titulada a través de un simple desembolso pecuniario. Como señaló José Manuel Díaz Blanco, el número de títulos nobiliarios enajenados en esta ciudad con motivo del casamiento real ascendió al menos a veintiuno ${ }^{30}$, siendo los compradores tanto miembros de algunas de las principales familias sevillanas -es el caso de los Saavedra, nuevos marqueses de Moscoso, o de los Céspedes, marqueses de Carrión-, como individuos procedentes del mundo del comercio que se habían enriquecido con los negocios de la Carrera de Indias.

El enlace real no fue el único acontecimiento del reinado que requirió de medios de financiación extraordinarios, pues la monarquía también tuvo que hacer frente a otros muchos gastos. En los momentos de mayor necesidad económica la venta de este tipo de mercedes debió intensificarse, dando lugar así a períodos de venalidad más acusados. Ante la carencia de una monografía relativa al periodo, es difícil establecer una cronología concreta relativa a las cifras de enajenación de títulos nobiliarios a lo largo del reinado de Carlos II. No obstante, hay algunas coyunturas que coinciden con el inicio de un conflicto bélico, en las cuales se observa un incremento significativo de la concesión de este tipo de mercedes probablemente por una mayor presencia de la venalidad. Tal es el caso del año 1683, en que se inició la Guerra de Luxemburgo, o de 1689, en que comenzó la

Castillo, F. y Galán Sánchez, Á. (eds.): Casas, Familias y Rentas. La nobleza del Reino de Granada entre los siglos XV-XVIII. Granada, 2010, pp. 283-301.

29. Antonio Frechilla, secretario real, sería nombrado depositario de los efectos beneficiados por dicha Junta. Archivo General de Simancas [en adelante AGS], Gracia y Justicia, lib. 362, fol. 47.

30. El autor se basa en una relación conservada en la Real Academia de la Historia que citó en su día don Antonio Domínguez Ortiz en uno de sus trabajos titulado «Documentos relativos a la historia de Sevilla y su antiguo reino", Archivo Hispalense, 113 (1966), pp. 257-260. José Manuel Díaz Blanco ha dedicado además dos de sus trabajos a analizar la trayectoria de algunas de estas familias de comerciantes como los Federighi, los Bucarelli o los Peralta, que vinieron a coronar su promoción con la compra de uno de los títulos nobiliarios beneficiados con motivo del casamiento del monarca. Vid. Díaz Blanco, J. M.: «Del "tratar noblemente" al trato de nobleza: el acceso al señorío de linajes extranjeros en Sevilla (ss. XVI-XVIII)» en Andújar Castillo, F. y Díaz López, J. P. (coords.): Los señoríos en la Andalucía Moderna. El Marquesado de los Vélez. Almería, 2007, pp. 623-638; «El ennoblecimiento en la carrera de Indias: el caso de la familia Peralta, marqueses de İscar» en Díaz López, J. P., Andújar Castillo, F. y Galán Sánchez, Á. (eds.): Casas, Familias y Rentas. La nobleza del Reino de Granada entre los siglos XV-XVIII. Granada, 2010, pp. 55-72. También encontramos referencias sobre los sevillanos que adquirieron sus títulos nobiliarios con motivo del casamiento real en CARTAYA BAÑos, J.: “"No se expresare en los títulos el precio en que compraron": los fundadores de la Maestranza de Caballería de Sevilla y la venta de títulos nobiliarios durante el reinado de Carlos II», Historia y Genealogía, 2 (2012) pp. 16-17. 
Guerra de los Nueve Años ${ }^{31}$ y además tuvo lugar el segundo enlace matrimonial de Carlos II con Mariana de Neoburgo ${ }^{32}$.

Más allá de que las ventas de títulos nobiliarios se incrementaran o disminuyeran en una coyuntura u otra, lo que está claro es que durante el reinado de Carlos II, como aseguró don Antonio Domínguez Ortiz, la enajenación de estos honores en los territorios de la Monarquía Hispánica fue descarada, llegando a adquirir proporciones sin precedentes ${ }^{33}$ que provocaron no solo la desvalorización social de estas mercedes, sino también su depreciación. El importe por el que llegaron a venderse los títulos nobiliarios fue tan bajo que incluso la propia Corona-máxima beneficiaria de aquella almoneda- se vio obligada a tomar medidas para frenar la fuerte caída que había experimentado la cotización de los títulos nobiliarios ${ }^{34}$. Así, por Real Cédula de 30 de agosto de 1692 dispuso que todos aquellos títulos que desde el 1 de enero de 1680 se hubieran concedido por menos de 30.000 ducados se declarasen vitalicios, debiendo pagar sus poseedores la diferencia hasta la referida cantidad para que se considerasen perpetuos ${ }^{35}$. Debido al gran malestar generado por aquella medida, la cantidad a entregar disminuyó hasta 22.000 ducados por un nuevo decreto dado en 16 de marzo de $1693^{36}$. Estas disposiciones no debieron

31. Rodríguez Hernández, A. J.: «La creación de Títulos de Castilla...», art. cit., pp. 186-187.

32. Maura Gamazo, G. (Duque de Maura): Vida y reinado de Carlos II. Madrid, 1990, pp. 348-365.

33. Domínguez Ortiz, A.: La sociedad española en el siglo XVII..., op. cit., vol. I, p. 212.

34. Aunque en España durante el siglo XVII los títulos nobiliarios se «beneficiaron» por precios bajos, no se llegó al extremo de Italia, donde estas mercedes se vendieron por cantidades tan bajas que llegaron incluso a provocar la denuncia del Consejo de Italia, que solicitó que los títulos solo pudieran enajenarse a través de él para controlar los precios y evitar así su desvalorización (Archivo Histórico Nacional [en adelante AHN], Estado, leg. 1939, exp. 3). Un trabajo de Vittorio Sciuti Russi da cuenta asimismo de las numerosas ventas de títulos que hubo en Sicilia, lo que se tradujo en la consiguiente devaluación de su precio entre 1600 y 1625. Vid. Sciuti Russi, V.: “"Incorrupta claritudo" versus “sordidade stirpes”» en Rivero Rodríguez, M. (coord.): Nobleza Hispana, Nobleza Cristiana. La orden de San Juan. Madrid, 2009, vol. I, pp. 191-208. Sobre la venta de títulos nobiliarios en Sicilia bajo el reinado de Felipe IV véase además Riвot García, L. A.: «La época del Conde-Duque de Olivares y el Reino de Sicilia» en Elliott, J. H. y García SAnz, Á. (coords.): La España del Conde Duque de Olivares. Valladolid, 1990, pp. 653-677, fundamentalmente, pp. 661-668. Para el estudio de esta temática durante el reinado de Carlos II son muy interesantes algunos trabajos de Antonio Álvarez-Ossorio Alvariño, quien ha abordado la venta de títulos nobiliarios en el Estado de Milán y el Reino de Nápoles. Vid. Álvarez-ossorio Alvariño, A.: La república de las parentelas. El Estado de Milán en la monarquia de Carlos II. Mantua, 2002; «La venta de magistraturas en el Reino de Nápoles durante los reinados de Carlos II y Felipe V», Chronica Nova, 33 (2007), pp. 57-94; «Las esferas de la Corte: príncipe, nobleza y mudanza en la jerarquía», en CHACón Jiménez, F. y Monteiro, N. G. (eds.): Poder y movilidad social. Cortesanos, religiosos y oligarquías en la Peninsula Ibérica (siglos XV-XIX). Madrid, 2006, pp. 170-180; «El gobierno de Milán» en MarTínez Millán, J. y Visceglia, M. A. (dirs.): La monarquía de Felipe III: Los Reinos. Madrid, 2008, vol. IV, p. 446.

35. Domínguez Ortiz, A.: La sociedad española en el siglo XVII..., op. cit., vol. I, p. 213.

36. El 14 de enero de 1694 se dio otra orden por la cual se declaraban perpetuos todos aquellos títulos de Castilla que habiendo sido concedidos desde 1680 hubieran demostrado no ser venales conforme a los requerimientos reales. AHN, Consejos, leg. 8975, exp. 15, fol. 7 r. 
surtir mucho efecto, pues años más tarde, el 18 de abril de 1695, fue necesario emitir otra nueva orden recordando que quienes no aprontasen aquella cantidad en un mes se verían privados de la perpetuidad de sus títulos ${ }^{37}$. Para llevar a cabo la medida impuesta por el rey fue preciso que la Cámara formara una serie de relaciones en las que debía indicar si había intervenido o no beneficio en la concesión de un título y si los titulares habían expedido los despachos de los mismos. Según Domínguez Ortiz, de aquellas relaciones resultó que al menos 56 títulos nobiliarios - de todos los concedidos hasta 1692- habían sido adquiridos por dinero, cifra que con toda seguridad debió de ser bastante mayor ${ }^{38}$. Del total de compradores hubo quien hizo perpetuo su título tras entregar los 22.000 ducados en que quedaron tasados estos honores, si bien, también existieron titulados que incapaces de aprontar la suma requerida, se resignaron a que sus títulos de condes o marqueses quedasen vitalicios y desaparecieran tras su muerte.

En cuanto a los procesos de solicitud y tramitación de títulos nobiliarios durante el siglo XVII, apenas podemos concluir nada a la espera de nuevos estudios monográficos que arrojen algo de luz al respecto. Aún así, a partir de las escasas, aunque útiles, referencias insertas en algunos trabajos recientes y de la consulta de documentación inédita, vamos a trazar en las páginas que siguen una visión general de quiénes fueron los titulados a lo largo de los reinados de Felipe IV y Carlos II, y de qué méritos y servicios se recompensaron con tan preciadas mercedes.

\section{RECOMPENSAR EL SERVICIO AL REY}

La nueva política de concesión de títulos nobiliarios, encaminada desde mediados del siglo xvir a recompensar mayoritariamente los servicios realizados a la Corona, provocó un cambio sustancial dentro de la propia nobleza titulada al otorgarle más importancia a los servicios personales que a los heredados. No obstante, durante el reinado de Felipe IV todavía siguieron concediéndose títulos en virtud de la sangre y de los méritos familiares ${ }^{39}$. Tal es el caso, entre otros, de Enrique Pimentel Guzmán, primogénito de la Casa de Távara, que obtuvo en 1625 el título de conde de Villada ${ }^{40}$; de Juan Francisco Silva Rivera, primogénito de la Casa de Montemayor, que recibió el título de marqués del Águila en 163941; o de segundones tales como Luis Fernández Portocarrero, hijo del segundo matrimonio

37. AHN, Consejos, leg. 9270.

38. Domínguez Ortiz, A.: La sociedad española en el siglo XVII..., op. cit., vol. I, p. 213.

39. Vid. Rodríguez Hernández, A. J.: «La creación de Títulos de Castilla...», art. cit., pp. 170-174.

40. Cfr. Alonso de Cadenas y López, A., Cadenas y Vicent, F. y Cadenas y Vicent, V.: Elenco de grandezas y títulos nobiliarios españoles. Madrid, 1990, p. 926.

41. Ibidem, p. 34. 
del conde de Palma del Río, quien sin opciones de heredar tituló en 1623 como marqués de Almenara; Juan Manuel Manrique de Zúñiga, segundo hijo del duque de Béjar, que obtuvo en 1636 el título de marqués de Valero; o Jerónimo Pimentel, octavo hijo del conde de Benavente, que recibió el marquesado de Bayona en 1625 en atención al esplendor de su Casa, pero también por sus propios méritos y servicios de carácter militar ${ }^{42}$. Ya con Carlos II, el número de títulos concedidos a miembros de Casas de la nobleza titulada comenzó a reducirse, siendo premiados en mayor medida los servicios que habían desempeñado los propios agraciados con estas mercedes. Para entonces, la riqueza y el favor se habían convertido en otras vías de acceso a la nobleza titulada, y por tanto, fueron muchos los que aprovechando estos nuevos «portillos» lograron acceder a lo más elevado del estamento privilegiado. Aún así, algunos de los títulos -intuimos que pocosvinieron a recaer todavía en miembros de prestigiosas familias ${ }^{43}$ como es el caso del marquesado de Menasalbas, concedido el 5 de marzo de 1666 a Juan Francisco Pacheco Téllez Girón «para los primogénitos de la Casa de Uceda ${ }^{44} »$, Casa con la que emparentó tras su enlace con Isabel María Francisca Téllez Girón Sandoval ${ }^{45}$.

Tanto en el reinado de Felipe IV como en el de Carlos II, las parentelas y clientelas de personajes destacados de la monarquía, como el Conde Duque de Olivares o Juan José de Austria, también se vieron ampliamente recompensadas con toda clase de mercedes y títulos nobiliarios. De este modo, Olivares, durante su valimiento, pudo colocar en los puestos más codiciados -aquellos que daban acceso directo al rey-a sus familiares y deudos ${ }^{46}$, propiciándoles así toda clase de

42. Vid. Rodríguez Hernández, A. J.: «La creación de Títulos de Castilla...», art. cit., p. 174.

43. Fueron igualmente titulados por pertenecer a Casas nobles, entre otros, Francisco Antonio Quijada Rebolledo y Quiñones, marqués de Inicio en 1690; José Pardo de Figueroa, marqués de la Atalaya en 1693; o Martín Carlos Laso de la Vega, marqués de la Cimada en 1694. El primero de ellos era hijo y heredero de Bernardino de Rebolledo, conde de Rebolledo, quien además de haber ejercido como consejero del Consejo de Guerra, había sido embajador de Felipe IV en Dinamarca entre los años 1648 y 1661 (AHN, Consejos, leg. 8975, exp. 9). José Pardo de Figueroa recibió el título en atención a los servicios de sus antepasados, a los suyos propios como capitán de infantería española durante una expedición contra los piratas del Mar del Sur, pero fundamentalmente por ser hijo legítimo de Baltasar Pardo de Figueroa, marqués de Figueroa (AHN, Consejos, leg. 8975, exp. 69). En el caso de Martín Carlos Laso de la Vega fue su tío, el conde de Puertollano, quien le solicitó el título nobiliario al haber recaído en su persona el mayorazgo de su madre, María Antonia Fernández de Mesa (AHN, Consejos, leg. 8975, exp. 91).

44. AHN, Consejos, leg. 5240.

45. Tras el fallecimiento de la abuela de esta, Juan Francisco Pacheco Téllez pasaría a ser duque de Uceda consorte. Cfr. Ozanam, D.: Les diplomates espagnols du XVIIIe siècle. Introduction et répertoire bibliographique. Madrid, 1998, p. 579.

46. Sus "partidarios naturales», como los define John Elliott, estarían unidos a él por lazos de parentesco, amistad, dependencia o procedencia regional, siendo miembros, en su mayoría, de las Casas de Zúñiga, Guzmán y Haro. Cfr. Elliott, J. H.: El conde-duque de Olivares..., op. cit., p. 153. 
cargos, honores y nombramientos en palacio ${ }^{47}$. Con esta política no solo benefició a los miembros de su facción, sino que también logró un mayor grado de fidelidad y control sobre ellos, procurándose así apoyos en los que sustentar su poder ${ }^{48}$.

Entre los años 1677 y 1678, predominó igualmente el patronazgo de Juan José de Austria, de modo que catalanes, aragoneses, castellanos y, en menor medida, valencianos, obtuvieron toda clase de mercedes -más de 200, según Henry Kamen ${ }^{49}$ - como premio a su fidelidad ${ }^{50}$. Cabe destacar que durante esos años se celebraron además las Cortes de Aragón, las cuales fueron aprovechadas igualmente por el bastardo de Felipe IV para recompensar con diversas gracias a todos aquellos que le habían apoyado en su ascenso al poder. A lo largo de esta etapa, entre los agraciados con títulos nobiliarios estuvieron Francisco Ramos del Manzano, consejero de Castilla y preceptor del rey, titulado conde de Francos en $1678^{51}$; el barón de Boil, Pedro Boil de Arenós, marqués en 168052; o José Ronquillo Briceño, conde de Gramedo en 1677, quien gozó de la protección de Juan José de Austria ${ }^{53}$.

Junto a los primogénitos y segundones de las principales Casas nobiliarias y las clientelas de Olivares o Juan José de Austria, también fueron recompensados con títulos nobiliarios las personas que dedicaron sus esfuerzos a servir al rey, quienes fueron conformando una nueva nobleza titulada de servicio que, como bien señaló John Elliott, ante las crecientes necesidades militares y administrativas de la monarquía, en una época de guerras y expansión territorial, supo aprovechar la posibilidad de acumular méritos y obtener mercedes, pues el servicio a la Corona permitió un espectacular ascenso social ${ }^{54}$.

47. Algunos de los nombramientos pueden verse en Elliott, J. H.: El conde-duque de Olivares..., op. cit., pp. 153-156.

48. Sobre el control y la distribución del patronazgo real en manos de validos como Lerma u Olivares, vid. Feros Carrasco, A.: «Lerma y Olivares: la práctica del valimiento en la primera mitad del seiscientos», en Elliott, J. H. y García SAnz, Á. (coords.): La España del Conde Duque de Olivares. Valladolid, 1990, pp. 209-216.

49. Kamen, H.: La España de Carlos II..., op. cit., p. 414.

50. SÁnchez Belén, J. A.: La política fiscal en Castilla durante el reinado de Carlos II. Madrid, 1997, p. 308.

51. Con anterioridad había desempeñado el cargo de gobernador interino del Consejo de Indias, por ausencia del conde de Peñaranda, y en 1683 fue nombrado consejero del Consejo de Hacienda. Vid. FAYARD, J.: Los ministros del Consejo real de Castilla (1621-1788). Informes biográficos. Madrid, 1984 , p. 37.

52. SÁnchez BeLén, J. A.: La política fiscal..., op. cit., p. 308.

53. La fidelidad mostrada por José Ronquillo al hermanastro de Carlos II le sirvió para integrarse por completo en el aparato del Estado de los Austrias. Sobre la familia Ronquillo Briceño, véase Salado Santos, J. M.: Al servicio del Rey. La familia Ronquillo Briceño (1550-1699). Córdoba, Universidad de Córdoba, Servicio de Publicaciones, 2009.

54. Elliott, J. H.: El conde-duque de Olivares..., op. cit., p. 32. 
Los títulos nobiliarios vinieron a recompensar, entre otros, los servicios prestados en la Corte. Algunos de ellos fueron títulos concedidos en calidad de mercedes dotales, las cuales eran concedidas por el rey a un hombre o una mujer que le había servido en su proximidad, con el fin de mejorar, en el caso de las mujeres, las condiciones de su propio casamiento, o, en el caso de los hombres, el de sus familiares, ya fueran hijas, hermanas o sobrinas ${ }^{55}$. Estas recompensas funcionaron además como un instrumento de refuerzo de los vínculos de los beneficiarios y beneficiarias con el soberano, propietario en última instancia de todos los empleos y de la dispensa de suertes ${ }^{56}$. Muchas de las mercedes dotales recayeron en las damas de la reina, quienes promocionaron a sus futuros maridos hasta la nobleza titulada. Tal es el caso de Margarita de Tábara -o Távara-, dama de la reina de origen portugués, que proporcionó en 1630 a su esposo, Iñigo Manrique de Lara, el título de conde de Frigiliana tras casar con él ${ }^{57}$; de Antonia de Borja Urrea, que convirtió a su marido, Pedro de Navarra, en marqués de Cabrega en 165458; de María Teresa Ronquillo Briceño -dama de honor de la reina Mariana de Austria y hermana de José Ronquillo Briceño, conde de Gramedo ${ }^{59}$-, que casó con Carlos Briceño Coloma en 1672, ascendiéndolo a marqués de Villanueva de las Torres ${ }^{60}$; o de doña Elena María de Gurrea Castro Pinós, quien en 1689 obtuvo un título de Aragón -el de marquesa de Castro Pinós, por despacho de 2 de julio de 1691- en agradecimiento a sus servicios como dueña de honor de la reina Mariana de Austria ${ }^{61}$. También obtuvieron títulos nobiliarios como premio a sus dilatados servicios en la cercanía de los monarcas, entre otros, los maestros de los príncipes ${ }^{62}$, los mayordomos reales, u otros cargos palatinos. Así sucedió, por ejemplo, con Jaime Manuel Manrique de Cárdenas, gentilhombre de Cámara del rey, que obtuvo en 1622 el título de marqués de Belmonte; con Juan de Vargas, primer caballerizo de la reina, que tituló como vizconde de Cerralvo en $1632^{63}$; o ya durante el reinado de Carlos II, con Jerónimo de Tordesillas, que recibió el título de conde de la Villa de Alcolea de Torote en mayo de 1697 en atención a los

55. Al respecto, Andújar Castillo, F.: «Mercedes dotales para mujeres, o los privilegios de servir en palacio (siglos XVII-XVIII)», Obradoiro de Historia Moderna, 19 (2010), pp. 215-247.

56. Bravo Lozano, J.: «Gracia y merced en época de desgracias...», art. cit., p. 113.

57. Cfr. Rodríguez Hernández, A. J.: «La creación de Títulos de Castilla...», art. cit., p. 176.

58. Andújar Castillo, F.: «Mercedes dotales para mujeres...», art. cit., p. 221.

59. Salado Santos, J. M.: Al servicio del Rey..., op. cit., pp. 22 y 121.

60. El título nobiliario data de 24 de julio de 1673. Cfr. Alonso de Cadenas y López, A., Cadenas y Vicent, F. y Cadenas y Vicent, V.: Elenco de grandezas..., op. cit., p. 948.

61. Casi diez años más tarde, el 22 de junio de 1700, el título se le permutó por uno de Castilla. AHN, Consejos, leg. 8975, exp. 38.

62. Así ocurrió con Juan de Isasi Idiáquez, maestro del príncipe Baltasar Carlos, quien recibió el título de Conde de Pie de Concha en 1638. Cfr. Rodríguez Hernández, A. J.: «La creación de Títulos de Castilla...», art. cit., p. 175.

63. Ibidem, pp. 175-176. 
servicios de sus antepasados y, sobre todo, por haber ejercido como menino de la reina Mariana de Austria ${ }^{64}$; o con Gonzalo Guillermo Fernández de Córdoba, que obtuvo idéntica merced en julio de 1698 por haber servido como paje del rey ${ }^{65}$.

Los servicios prestados en el ejército fueron igualmente recompensados durante el siglo XviI con numerosos títulos nobiliarios ${ }^{66}$. Tal es el caso, entre otros, de Fadrique de Toledo Osorio, que obtuvo en 1624 el título de marqués de Valdueza tras servir como Almirante de la Armada del mar océano y como Capitán General del reino de Portugal; de Diego Mesía, marqués de Leganés en 1627 , quien además de contar con sobrados méritos militares era el cuarto hijo del primer duque de Uceda ${ }^{67}$; de Francisco Antonio Agurto Salcedo, caballero de la orden de Alcántara y Gobernador General de Flandes, quien en décadas posteriores, concretamente en 1686, obtuvo el título de marqués de Gastañaga en atención a sus servicios militares ${ }^{68}$; o bien, de Félix Nieto de Silva, consejero del Consejo de Guerra, que fue recompensado en 1688 con el título de marqués de Tenebrón-del cual sacaría despacho su hijo en 1693-para premiar su larga trayectoria militar por espacio de treinta y ocho años, tiempo en que había servido diversos puestos como los de gobernador de las plazas de Alcántara y Cádiz, gobernador y Capitán General de las Islas Canarias, presidente de su Audiencia, Asistente de la ciudad de Sevilla, maestre de campo general de las milicias de dicha ciudad, y gobernador y Capitán General de las plazas de Orán y Mazalquivir ${ }^{69}$.

Los servicios desempeñados en cargos políticos, administrativos o de justicia, también fueron premiados con idénticas mercedes en muchos casos. Así sucedió con Diego de Riaño y Gamboa, que obtuvo en 1659 el condado de Villariezo tras desempeñar los puestos de fiscal y presidente de la Chancillería de Valladolid, oidor de Granada, visitador de los tribunales de Sicilia, Fiscal del Consejo Real y Presidente de Castilla ${ }^{70}$, o con Juan de Andicano, que había servido como fiscal del crimen y de lo civil, oidor de la Chancillería de Valladolid, Alcalde de Casa y Corte, fiscal y consejero del Consejo de Castilla, asesor del Consejo de Guerra, y había estado al frente de diversas Juntas que se formaron para aprontar medios económicos, entre ellas la «Junta de Medios, de Encabezamientos y Millones». En recompensa por todo ello se le otorgó en abril de 1689 el título de conde de

64. AHN, Consejos, leg. 8975, exp. 107.

65. AHN, Consejos, leg. 8975, exp. 113.

66. Para el reinado de Carlos II, Fantoni y Benedi cifra en setenta y dos los títulos nobiliarios que se concedieron a militares durante este periodo. Vid. FANTONI y BENEDI, R.: «Títulos y Grandezas de España concedidos al estamento militar por Carlos II (1665-1700)», Emblemata, 13 (2007), pp. 257-270.

67. Vid. Rodríguez Hernández, A. J.: «La creación de Títulos de Castilla...», art. cit., p. 176.

68. Cfr. Maura Gamazo, G. (Duque de Maura): Vida y reinado de Carlos II..., op. cit., p. 314.

69. AHN, Consejos, leg. 8975, exp. 60.

70. Domínguez Ortiz, A.: La sociedad española..., op. cit., p. 210. 
Monterrón ${ }^{71}$. Los títulos nobiliarios recayeron además, aunque en menor medida, en algunos de los procuradores de las ciudades con derecho a voto que apoyaron la prorrogación de los servicios de millones y otros donativos para la Corona. Un ejemplo lo tenemos en Francisco Manuel Ruiz, caballero de Alcántara y veinticuatro de Córdoba, que obtuvo la distinción de conde de Santa Cruz de los Manueles en septiembre de $1688^{72}$, por haber asistido con su voto a los servicios que había hecho la ciudad de Córdoba y, especialmente, por haber apoyado las prorrogaciones de millones de los años 1669 y 1673.

En otras ocasiones, los titulados fueron personas que recibieron estas mercedes en virtud de los servicios de algún pariente religioso -normalmente un tío o un hermano- que había desempeñado importantes cargos, tanto eclesiásticos como políticos y de gobierno. Es el caso, entre otros, de Diego de Guzmán, que tituló como marqués de Cardeñosa en 1634 por los méritos de su tío, el Arzobispo de Sevilla; o de Francisco Manso, conde de Hervias en 1651, que obtuvo el título en atención a los servicios de su tío, el Arzobispo de Burgos ${ }^{73}$. De forma similar, Iñigo Rodolfo Fernández de Angulo recibió el título de marqués de Hinojares en 1690 gracias a su hermano, don Diego Fernández de Angulo y Sandoval, obispo de Ávila y embajador extraordinario en Portugal ${ }^{74}$; y Bartolomé de Espejo y Cisneros tituló como marqués de Olías en 1699 por los méritos de su tío, llamado igualmente Bartolomé de Espejo y Cisneros, quien además de haber sido obispo de Málaga, había desempeñado los puestos de gobernador del Consejo de Navarra, del Consejo de Hacienda y de consejero del Consejo de Castilla ${ }^{75}$.

Por último, se otorgaron títulos nobiliarios a individuos o familias que disponían de la distinción de vizcondes con anterioridad. Así sucedió con los vizcondes de Castejón, quienes obtuvieron este título por despacho de septiembre de 1647 expedido en cabeza de Gracián de Beaumont y Navarra, en atención a sus servicios y a los que habían hecho sus antecesores, todos ellos «del mayor lustre y antigüedad ${ }^{76} »$. Atendiendo a los mismos motivos, por consulta de la Cámara de Castilla de 7 de marzo de 1682, se hacía merced de título de marqués de Santa Clara a Joaquín Antonio de Beaumont y Navarra, hijo legítimo del dicho Gracián de Beaumont ${ }^{77}$.

71. AHN, Consejos, leg. 8975, exp. 5.

72. El despacho es de 15 de febrero de 1693. AHN, Consejos, leg. 8975, exp. 63.

73. Rodríguez Hernández, A. J.: «La creación de Títulos de Castilla...», art. cit., p. 177.

74. AHN, Consejos, leg. 8975, exp. 25.

75. AHN, Consejos, leg. 8975, exp. 118.

76. Sobre los Beaumont, vid. Garrido Yerobi, I.: Los Beaumont. Un linaje navarro de sangre real (estudio histórico-genealógico). Sevilla, Fabiola de Publicaciones Hispalenses, 2007.

77. El despacho fue expedido el 28 de junio de 1693. AHN, Consejos, leg. 8975, exp. 51. 


\section{RECOMPENSAR LOS SERVICIOS PECUNIARIOS}

A lo largo del siglo xviI, junto a los méritos expuestos con anterioridad, los servicios pecuniarios o económicos también posibilitaron la obtención de un título nobiliario. Durante el reinado de Felipe IV, la venta de estos honores fue reducida ${ }^{78}$, incluso es posible que fuera el primer monarca en vender títulos nobiliarios, pues no hay constancia de este tipo de enajenaciones en los reinados precedentes. Sin embargo, con Carlos II la venta de títulos nobiliarios aumentó de forma considerable, sobre todo en aquellas coyunturas en que las demandas económicas de la monarquía fueron mayores. La continua necesidad de liquidez por parte de la Corona y la gran demanda social de títulos nobiliarios, estimuló por tanto la diversificación de los sistemas de enajenación de estas mercedes, los cuales pervivieron, sin apenas cambios, a lo largo del siglo XviII ${ }^{79}$. De este modo, se adquirieron títulos mediante el desembolso directo de una cantidad monetaria determinada, o bien, a través de procedimientos de compra indirectos que implicaron igualmente la inversión o cesión de un monto de dinero a la Corona.

Buena parte de los títulos nobiliarios enajenados a lo largo del siglo Xvir fueron vendidos a través de conventos, monasterios $\mathrm{u}$ otras instituciones religiosas a las que el monarca concedió títulos en blanco para que con el producto de su venta pudieran financiar la reparación o construcción de sus edificios o iglesias ${ }^{80}$. Este sistema tuvo sus inicios, por lo que sabemos hasta ahora, hacia 1623, fecha en la que Felipe IV, por medio de un decreto, dio cuenta al conde de Monterrey de que había concedido al convento de Guadalupe un título de marqués en Italia para beneficiar y costear con su producto varias obras ${ }^{81}$. No obstante, el mayor desarrollo de este sistema de

78. Más frecuente fue la venta de otros honores, tales como los hábitos de las Órdenes Militares. Véase al respecto: Postigo Castellanos, E.: Honor y privilegio en la Corona de Castilla. El Consejo de las Órdenes y los caballeros de hábito en el siglo XVII. Valladolid, 1988, pp. 122-125; WRIGHT, L. P.: «Las Órdenes Militares en la sociedad española de los siglos XVI y XVII. La encarnación institucional de una tradición histórica» en ElliotT, J. H. (ed.): Poder y sociedad en la España de los Austrias. Barcelona, 1982, pp. 15-56; Jiménez Moreno, A.: «Honores a cambio de soldados, la concesión de hábitos de las Ordenes Militares en una coyuntura crítica: la Junta de Hábitos (1635-1642)» en Soria Mesa, E. y Molina Recio, R. (eds.): Las élites en la época moderna: la Monarquía española. Familia y redes sociales. Córdoba, 2009, vol. II, pp. 155-172; Giménez Carrillo, D. M.: «La venta de hábitos de las Órdenes Militares en el siglo XVII. Entre la ocultación y el delito de simonía», en Andújar Castillo, F. y Felices de la Fuente, M. M. (eds.): El poder del dinero. Ventas de cargos y honores en la España del Antiguo Régimen. Madrid, 2011, pp. 297-309.

79. Vid. Felices de la Fuente, M. M.: La nueva nobleza titulada de España y América en el siglo XVIII (1701-1746). Entre el mérito y la venalidad. Almería, Universidad de Almería, Servicio de Publicaciones, 2012.

80. Sobre la enajenación de títulos nobiliarios a través de instituciones religiosas, vid. AndúJAR Castillo, F. y Felices de la Fuente, M. M.: «Nobleza y venalidad: el mercado eclesiástico de venta de títulos nobiliarios en el siglo XVII», Chronica Nova, 33 (2007), pp. 131-153.

81. Domínguez Ortiz, A.: La Sociedad Española..., op. cit., p. 211. 
enajenación tuvo lugar con Carlos II, período en el que se concedieron tantos títulos nobiliarios para beneficiar que las instituciones religiosas fueron incapaces de venderlos todos ante la gran oferta existente. Algunos de los adquirientes fueron Pedro José de Molina Junterón -del linaje murciano de los Molina, uno de los más ilustres de la ciudad, emparentados con toda la elite y nobleza titulada de la zona-, quien compró su título de marqués de Corvera al convento de San Jerónimo de Madrid en $1685^{82}$, o Juan Fernández de Córdoba Lisón y Contreras, que formaba parte de una familia perteneciente a la oligarquía granadina que había logrado promocionar socialmente a lo largo de dos siglos, gracias, fundamentalmente, a cuidadas estrategias matrimoniales y a la acumulación de mayorazgos ${ }^{83}$. Tras adquirir la jurisdicción de Algarinejo en agosto de 1682 por 3.200.000 maravedíes ${ }^{84}$, el siguiente paso fue titularse marqués de aquella villa, honor que logró tras comprarlo en 1690 a la Catedral de Granada ${ }^{85}$.

A través de la financiación de nuevas unidades militares se obtuvieron también diversos títulos nobiliarios a lo largo del siglo xvir, tal y como lo han puesto de manifiesto los recientes trabajos de Francisco Andújar Castillo o de Antonio José Rodríguez Hernández ${ }^{86}$. Este sistema, que surgió a finales de la década de $1630^{87}$

82. El título de marqués de Corvera recayó sobre 317 fanegas de tierra que poseía la familia Molina en Corvera, Murcia. GiRón Pascual, R. M.: «Patrimonio, mayorazgo y ascenso social en la Edad Moderna: la familia de los Bustos antes y después del marquesado de Corvera (ss. XVI-XIX)» en Díaz López, J. P., Andújar Castillo, F. y Galán Sánchez, Á. (eds.): Casas, Familias y Rentas. La nobleza del Reino de Granada entre los siglos XV-XVIII. Granada, 2010, pp. 327-353.

83. Sobre el proceso de ascenso social de los señores de Algarinejo, vid. SorIA MEsA, E.: «El señorío de Algarinejo (siglos XVI-XVIII)", Revista del Centro de Estudios Históricos de Granada y su Reino, 6 (1992), pp. 319-334.

84. Ibidem, p. 333.

85. AHN, Consejos, leg. 2752. La compra se ocultó en el despacho del título, haciendo constar en él únicamente los servicios de Juan Fernández de Córdoba como gentilhombre de boca del rey y señor de Algarinejo (AHN, Consejos, leg. 8975, exp. 11).

86. Vid. entre otros, ANDÚJAR CASTILLO, F.: «Empresarios de la guerra y asentistas de soldados en el siglo XVII», en García Hernán, E. y MafFi, D. (eds.): Guerra y sociedad en la Monarquía Hispánica. Política, estrategia y cultura en la Europa Moderna (1500-1700). Madrid, 2006, vol. II, pp. 375-394; «Milicia y nobleza. Reformulación de una relación a partir del caso granadino (siglos XVII-XVIII)» en Jiménez Estrella, A. y Andújar Castillo, F. (eds.): Los nervios de la guerra. Estudios sociales sobre el ejército de la monarquía hispánica (s. XVI-XVIII): nuevas perspectivas. Granada, 2007, pp. 251-276. Rodríguez Hernández, A. J.: «La creación de Títulos de Castilla...», art. cit., pp. 178-180; del mismo autor, «La venta de títulos nobiliarios a través de la financiación de nuevas unidades militares durante el siglo XVII» en Andújar Castillo, F. y Felices de la Fuente, M. M. (eds.): El poder del dinero. Venta de cargos y honores en la España del Antiguo Régimen. Madrid, 2011, pp. 270-296; y «Movilidad, venalidad y ascenso social en los ejércitos de la Monarquía Hispánica durante el siglo XViI» en Imízcoz Beunza, J. M. y Chacón Jiménez, F. (eds.): Procesos de movilidad social en la España moderna. Elites, redes y monarquía. Madrid, Sílex [en prensa]. Agradezco al autor su generosidad por permitirme consultar este trabajo antes de ver la luz impresa.

87. No obstante, el reclutamiento de compañías a expensas de su reclutador es un fenómeno que ya había aparecido de manera puntual durante el reinado de Felipe II. Cfr. Rodríguez Hernández, A. J.: «Movilidad, venalidad y ascenso social...», art. cit., (en prensa). 
y se prolongó en las sucesivas crisis bélicas hasta desarrollarse de forma masiva en el reinado de Carlos II, sobre todo a partir de $1680^{88}$, perviviría hasta 1704 , año en el que se registraron las últimas levas de regimientos a cambio de títulos nobiliarios con motivo de la Guerra de Sucesión ${ }^{89}$. Normalmente, la recluta consistía en aportar un determinado número de hombres -entre 500 y 800 , variando el número en función de lo pactado, de la experiencia militar acumulada por el que reclutaba, de su origen familiar o de las condiciones de reclutamiento ${ }^{90}-$, vestidos y armados, y a cambio, se obtenía un título de conde o marqués y las respectivas patentes en blanco para los oficiales de las nuevas tropas que se levantaban. La efectividad de este sistema de levantamiento de nuevas unidades militares por particulares y la incapacidad económica de la Real Hacienda para hacer frente por sí misma a los reclutamientos, provocó el aumento de este tipo de asientos ${ }^{91}$. Por otro lado, la obtención de títulos nobiliarios a cambio de financiar nuevas levas beneficiaba tanto a la Corona como a los futuros titulados, pues aquella lograba proveerse de hombres y conseguir además ingresos con el abono de los derechos de los títulos nobiliarios -lanzas y medias annatas-, mientras que los reclutadores consideraban, de cara a la sociedad, que la concesión del título estaría más justificada, al tratarse de un servicio basado en el levantamiento de una serie de hombres y no en un pago monetario. No obstante, el servicio de la recluta comportaba una inversión económica idéntica a la que precedía en otras compras de títulos nobiliarios que implicaban un desembolso en metálico, por lo que de un modo u otro, la «venta» se consumaba igualmente. Los beneficiarios de este sistema de reclutamiento y de su financiación fueron principalmente las oligarquías de las ciudades, los poderosos de los reinos y los «empresarios» particulares que se aventuraban a hacer sus inversiones a cambio de los despachos de oficiales del ejército y de los honores mencionados ${ }^{92}$.

Algunos ejemplos de los títulos nobiliarios que se concedieron en tiempos de Felipe IV por medio de la financiación de hombres son, entre otros, los de Luis Ortiz Zúñiga, que sirvió en 1639 con 300 infantes, recibiendo a cambio el título de marqués de Valencina; el de José de Saavedra, que obtuvo el título de marqués de Rivas, en 1641, por levantar a su costa un Tercio de soldados valones ${ }^{93}$; o el del

88. Ibídem.

89. Vid. Felices de la Fuente, M. M.: La nueva nobleza titulada..., op. cit., pp. 287-294.

90. Rodríguez Hernández, A. J.: «Movilidad, venalidad y ascenso...», art. cit., (en prensa).

91. Ibídem.

92. Cfr. Andújar Castillo, F.: «Milicia y nobleza. Reformulación de una relación...», art. cit., p. 260.

93. Domínguez Ortiz, A.: La Sociedad Española..., op. cit., p. 212. Estas mercedes y otras, así como la denegación de algunas propuestas de conseguir un título nobiliario a cambio de reclutar hombres, han sido abordadas en Rodríguez Hernández, A. J.: «La venta de títulos nobiliarios a través de la financiación...», art. cit., pp. 278-282. 
vizcaíno Pedro de Villela Zorrilla y Arce que tituló como conde de Lences en 1650 , tras ajustar un asiento con la Corona en 1649 , por el que se comprometía a reclutar 800 hombres ${ }^{94}$. Cabe destacar además, que en 1640 se concedieron diez Grandezas de España a algunas Casas nobiliarias que se comprometieron a servir con 400 o 500 infantes para el ejército de Cataluña ${ }^{95}$. Evidentemente, las necesidades bélicas de la monarquía marcaron los ritmos de formación de las nuevas unidades militares, de modo que durante las coyunturas en las que hubo guerras se requirió un mayor suministro de hombres, como sucedió durante las dos últimas décadas del reinado de Carlos II, coincidiendo con la Guerra de Luxemburgo (1683-1684) y la Guerra de los Nueve Años (1688-1697) ${ }^{96}$. En 1683 se firmó un primer asiento con Cristóbal Moscoso, mediante el cual recibió el título de conde de las Torres de Alcorrín a cambio de reunir 400 hombres, y al año siguiente, en 1684, fueron al menos dos las personas que se ennoblecieron por este sistema del reclutamiento: Cristóbal del Castillo Fajardo, titulado marqués de Cuevas del Becerro ${ }^{97}$, y Juan de la Cerda Ponce de León, marqués del Castillo del Valle de Sidueña ${ }^{98}$, quienes se comprometieron a servir con un Tercio de 400 hombres a cambio de la concesión de sendos títulos nobiliarios. Años más tarde, durante la Guerra de los Nueve Años, Nicolás Rioja Zúñiga logró titular también como conde de Riomolinos, por decreto de 1 de mayo de 1692, tras reclutar un Tercio, servicio que se hizo constar en el despacho del título nobiliario ${ }^{99}$.

Los grandes hombres de negocios de la monarquía, entre ellos asentistas y banqueros ${ }^{100}$, también consiguieron titular por sus servicios como financieros

94. Rodríguez Hernández, A. J.: «La creación de Títulos de Castilla...», art. cit., pp. 179-180.

95. Domínguez Ortiz, A.: La Sociedad Española..., op. cit., p. 218.

96. Las reclutas que tuvieron lugar durante estos años y los títulos que se concedieron merced a ellas, pueden consultarse en Rodríguez Hernández, A. J.: «La venta de títulos nobiliarios a través de la financiación...», art. cit., pp. 283-296.

97. El título fue despachado en 1693. AHN, Consejos, leg. 9875, exp. 67. Referencia a la misma compra en ANDÚJAR CASTILlo, F.: «Empresarios de la guerra y asentistas de soldados...», art. cit., p. 379.

98. Rodríguez Hernández, A. J.: «El reclutamiento de españoles para el Ejército de Flandes durante la segunda mitad del siglo XVII», en García Hernán, E. y MafFI, D. (coords.): Guerra y sociedad en la monarquía hispánica: política, estrategia y cultura en la Europa moderna (1500-1700). Madrid, 2006, vol. II, p. 407.

99. AHN, Consejos, leg. 8975, exp. 75.

100. Sobre estos grupos de financieros y sus relaciones durante las últimas décadas del siglo XVII, vid. Dedieu, J. P.: «Grupos financieros al servicio del rey de España. Fines del siglo XVII - principios del XVIII", en Dubet, A, Luis, J. P. (dirs.): Les financiers et la construction de l'Etat. France Espagne (XVIIe-XIXe siècles), Presses Universitaires de Rennes, 2011, pp. 87-104 (disponible electrónicamente en: <alshs.archives-ouvertes.fr/docs/00/44/45/81/PDF/Entreprises_esp.pdf>). Existen además algunos trabajos que han abordado el ennoblecimiento de estos hombres. Véase SANZ Ayán, C.: Los banqueros de Carlos II. Valladolid, 1989, pp. 454-457; Soria MesA, E.: La nobleza en la España Moderna..., op. cit., p. 87; SÁnchez BeléN, J. A.: La política fiscal en Castilla..., op. cit., p. 309. 
reales, bien a cambio de desembolsar una cuantía determinada de dinero, o en virtud de alguno de los asientos que firmaban con la Corona, los cuales a veces incluían cláusulas relativas a la percepción de un título nobiliario u otras mercedes. Casi todos estos hombres de negocios siguieron trayectorias muy similares, pues en gran parte de los casos, tras acumular cuantiosos beneficios económicos, lograban introducirse en el aparato de gobierno de la monarquía ocupando relevantes puestos -normalmente de Hacienda- que les reportaban prestigio social, a la vez que les permitían controlar los resortes del poder y sus propios intereses monetarios. El siguiente paso era invertir en la compra de algún señorío u honor, como los hábitos de las Ordenes Militares o los títulos nobiliarios. Situados en lo más alto de la jerarquía social y una vez consolidado el ascenso, intentarían borrar para siempre unos orígenes de los que no solían sentirse orgullosos. Algunos de los financieros titulados durante el reinado de Felipe IV por sus servicios económicos prestados durante años ${ }^{101}$, fueron Ambrosio Spínola, que obtuvo en diciembre de 1621 el marquesado de los Balbases y la naturaleza para él y sus hijos ${ }^{102}$, José Strata Spínola, que en 1649 recibió el título de marqués de Robledo de Chavela ${ }^{103}$, Juan Esteban Imbrea y Franquis, conde de Yebes el mismo año, o Juan Francisco Balbi, que tituló como conde de Villalvilla en $1650^{104}$.

Entre 1672 y 1675, Carlos II también ennobleció a algunos de los banqueros reales más representativos. Agraciados con estas mercedes nobiliarias fueron, entre otros, Manuel José Cortizos, quien adquirió el título de marqués de Villaflores en $1672^{105}$, Pedro Fernández del Campo y Angulo, titulado como marqués de Mejorada del Campo en $1673^{106}$, Benito Galindo Piquinotti, marqués de Villaleal

101. Sobre los hombres de negocios de Felipe IV, vid. Domínguez Ortiz, A.: Política y hacienda de Felipe IV. Madrid, 1983, pp. 103-147.

102. Cfr. Rodríguez Hernández, A. J.: «La creación de Títulos de Castilla...», art. cit., p. 178.

103. Domínguez Ortiz, A.: Política y hacienda de Felipe IV..., op. cit., p. 115.

104. Soria Mesa, E.: La nobleza en la España..., op. cit., p. 87. La Corona dejó a deber grandes cantidades a Juan Francisco Balbi, siendo la situación de su casa de negocios tan precaria que el mismo año que obtuvo el título nobiliario, en 1650, se declaró en quiebra. Quizás sea una simple coincidencia el hecho de que el título se concediera el mismo año en que finalizó su actividad económica, no obstante, es muy probable que la merced se otorgara entonces para compensar las deudas y para remunerar los servicios monetarios prestados hasta entonces a la Corona. Vid. Domínguez OrTiz, A.: Política y hacienda de Felipe IV..., op. cit., p. 119.

105. AHN, Consejos, lib. 2752. La trayectoria de los Cortizos, una familia de financieros judeoconversos procedente de Braganza y establecida en Castilla hacia la segunda mitad del reinado de Felipe II, cuyos miembros fueron importantes hombres de negocios de la monarquía, ha sido abordada en SAnz Ayán, C.: «Consolidación y destrucción de patrimonios financieros en la Edad Moderna: Los Cortizos (1630-1715)» en Robledo Hernández, R. y Casado Alonso, H. (coords.): Fortuna y negocios: formación y gestión de los grandes patrimonios (siglos XVI-XX). Valladolid, 2002, pp. 73-98.

106. Pedro Fernández del Campo había sido alcalde de Bilbao - puesto que, junto al de regidor, también había ejercido su padre- y gozaba de una gran fortuna producto del comercio y de la propiedad de numerosas tierras. Cfr. Sánchez Belén, J. A.: La política fiscal..., op. cit., p. 308. Referencias 
en $1675^{107}$, o Ambrosio de Onís (Donis), quien obtuvo unos años más tarde, en 1680, el marquesado de Olivares de Duero tras pagar 50.000 ducados $^{108}$.

Entre los grandes financieros que obtuvieron sus títulos nobiliarios tras desembolsar una cuantía determinada de dinero, sobresale la familia Grillo, quienes desde finales de la década de 1670 se habían hecho esenciales para la monarquía en la provisión de dinero para los ejércitos de Milán y Flandes. En 1683, Francisco Grillo, previo pago de 50.000 escudos para asistir al marqués de Leganés en Milán, consiguió el título de marqués de Clarafuente ${ }^{109}$, y poco después, en 1691, su sobrino y heredero, Marco Antonio Grillo, obtuvo la dignidad de Grande, por la que pagó la desorbitada cifra de $300.000 \operatorname{pesos}^{110}$. El título de conde de Moriana fue igualmente adquirido en 1698 por el financiero Juan de Horcasitas y Avellaneda, quien a comienzos del reinado de Felipe $\mathrm{V}$ iba a estar al frente de la Tesorería Mayor de Guerra ${ }^{111}$.

Los asientos firmados con la Corona también pudieron incluir la obtención de un título nobiliario o de otras mercedes como los hábitos de las Órdenes Militares. Muestra de ello es el título de vizconde de Torrecilla y Peñatejada que recibió Félix Ventura de Aguerri en virtud de un asiento ajustado con su padre, José Aguerri Churruca, el cual fue recompensado a su vez en 1687 con el título de marqués de Valdeolmos, perpetuo desde $1695^{112}$.

también en Fernández de Pinedo y Fernández, E.: Crecimiento económico y transformaciones sociales del País Vasco (1100-1850). Madrid, 1974, p. 59. Además se labró una carrera al servicio de la Corona mediante el desempeño de numerosos puestos, tales como los de secretario del Consejo de Guerra, del Consejo de Estado, consejero camarista de la Cámara de Indias, consejero de Guerra y, finalmente, consejero supernumerario de Hacienda. El título se le concedía tras casi 30 años de servicios. Cfr. Escudero, J. A.: Los secretarios de Estado y del despacho (1474-1724). Madrid, 1976, vol. I, p. 270.

107. SÁnchez Belén, J. A.: La política fiscal..., op. cit., p. 308. Sobre la firma de los Piquinotti, vid. SAnz Ayán, C.: Los banqueros de Carlos II..., op. cit., pp. 323-324. También, Domínguez Ortiz, A.: Politica y hacienda de Felipe IV..., op. cit., p. 113.

108. Los Donis, al igual que los Cortizos, fueron otra familia de portugueses conversos que tras emigrar a la Península y modificar sus apellidos se enriquecieron con el comercio y las finanzas, llegando a ser importantes asentistas del rey. Véase al respecto SANZ Ayán, C.: «Blasones son escudos. El ascenso económico y social de un asentista del rey en el siglo XviI: Bentura Donis», Cuadernos de Historia Moderna, 20 (1998), pp. 33-57.

109. Cfr. Sánchez Belén, J. A.: La política fiscal en Castilla..., op. cit., p. 309.

110. Cfr. Soria Mesa, E.: La nobleza en la España Moderna..., op. cit., p. 69.

111. Juan de Horcasitas procedía de una familia hidalga del valle de Arcentales, en las Encartaciones de Vizcaya. Cfr. Castro, C. de: A la sombra de Felipe V. José de Grimaldo, ministro responsable (1703-1726). Madrid, 2004, p. 74. Su hermano mayor, Francisco de Horcasitas, se había enriquecido comerciando en Madrid con el hierro en barras y en planchas que hacía traer de su tierra natal, y con la participación en el lucrativo comercio de la exportación de lanas finas. Sobre su trayectoria: Bravo Lozano, J.: «Don Francisco de Horcasitas. Las posibilidades de Madrid a fines del siglo XVII», Estudios de Historia Social, 36-37 (1986), pp. 497-521.

112. Cfr. SÁnchez Belén, J. A.: La política fiscal en Castilla..., op. cit., p. 309. 
Del mismo modo, la cancelación de créditos y deudas que estos financieros mantenían contra la Real Hacienda por los numerosos asientos y préstamos realizados a la monarquía, también permitió obtener una distinción nobiliaria. El título de marqués de Cela, otorgado en junio de $1699^{113}$, fue precisamente una compensación por los créditos que la Corona debía al asentista José Francisco Guerrero Chavarino, titulado desde 1691 como conde de Buenavista ${ }^{114}$, del tiempo que había ejercido como proveedor de la plaza de Ceuta por medio de Gabriel de Campos ${ }^{115}$. Asimismo, Diego Fernández Tinoco también fue nombrado vizconde del Fresno en 1680 , por renunciar a favor de la hacienda regia unas cantidades adeudadas ${ }^{116}$.

Durante el siglo xvII, la adquisición de títulos nobiliarios mediante la cancelación de deudas mantenidas con la Real Hacienda también proporcionó a algunos individuos títulos nobiliarios, pues la Corona, incapaz de satisfacer sus pagos, vio en esta fórmula de compensación una manera eficaz de cancelar sus atrasos sin necesidad de tener que desembolsar cuantía alguna. Los particulares, por su parte, también se beneficiaban de este sistema de retribución, pues conscientes de la insolvencia económica de las arcas reales para hacer frente a sus pagos, vieron en este medio una forma eficaz de rentabilizar la pérdida de unos créditos que nunca cobrarían. El procedimiento consistía en conceder un título nobiliario a los acreedores, a cambio de que estos renunciaran a las cantidades que se les estaban debiendo. Era, por tanto, un sistema de resarcimiento que, a todas luces, suponía la compra directa del honor. Alonso de Cárdenas y Peralta, vizconde de Ambite y gentilhombre de boca, fue uno de los interesados en cancelar sus deudas con la Corona a cambio de que su título de vizconde pasara a ser de marqués. Así lo hizo constar en un memorial remitido a la Cámara de Castilla, donde además de dar cuenta de los méritos de su tío, Alonso de Cárdenas, y de su padre, que había servido treinta y ocho años en el gobierno de Málaga y en Cataluña, exponía que había perdido 12.000 ducados de renta por haberlos puesto a disposición de la Corona ${ }^{117}$. En consideración a todo ello, y fundamentalmente a la cesión de aquella cantidad, solicitó que se le honrase con el título de marqués de Ambite, asegurando tener las calidades necesarias y ser hermano de madre del marqués de Mondejar.

La adquisición de un título nobiliario mediante un pago directo a la hacienda regia fue uno de los sistemas más empleados para hacerse con estas mercedes, sobre

113. AHN, Consejos, leg. 8975, exp. 122. La merced recayó en su hermano Esteban Guerrero Chavarino (o Chafarino).

114. Cfr. Alonso de Cadenas y López, A., Cadenas y Vicent, F. y Cadenas y Vicent, V.: Elenco de grandezas y títulos..., op. cit., p. 161.

115. AGS, Contadurías Generales, leg. 189.

116. Cfr. SÁnchez Belén, J. A.: La politica fiscal en Castilla..., op. cit., p. 309. Datos además en SAnZ Ayán, C.: Los banqueros de Carlos II..., op. cit., p. 351-352.

117. AHN, Consejos, leg. 8975, exp. 2. 
todo en tiempos de Carlos II, aunque también se constatan algunos casos durante el reinado de Felipe IV. Así lo demuestra el caso de Francisco Félix Beltrán de Caicedo, un rico encomendero indiano que intentó titularse en 1648 como conde de Suesca ofreciendo 40.000 ducados $^{118}$, o de Agustín de Villavicencio, quien adquirió en 1667 el marquesado de Alcántara del Cuervo por 70.000 pesos $^{119}$. Sabemos además que entre 1667 y 1668, se concedieron varios títulos nobiliarios en blanco al secretario real Blasco de Loyola para que los beneficiase y lograra así medios económicos para financiar la guerra contra Francia. De estos títulos, al menos dos fueron adquiridos a lo largo de 1668, siendo sus compradores Francisco Hurtado Mendoza, quien tituló como marqués de Fregenal ${ }^{120}$, y Andrés Fernández de Córdoba, que tituló como conde de Torres Cabrera ${ }^{121}$. Empleando este mismo sistema adquirió su título Esteban Chilton Fantoni, descendiente de un linaje mercantil de origen florentino que se estableció en Cádiz hacia el siglo XvI ${ }^{122}$. Esta familia enriquecida en el comercio con Indias, logró prosperar y ocupar una regiduría perpetua en el cabildo gaditano, integrándose así en la oligarquía local. Su proceso de ascenso social se consolidó con una serie de matrimonios ventajosos ${ }^{123}$ y con la obtención del título de conde de Jimena de Líbar, adquirido en 1684 por 20.000 ducados $^{124}$.

A lo largo del siglo Xvil, también se documentan ventas privadas de títulos nobiliarios entre particulares que, o bien acumularon más de un título y lograron la autorización regia para enajenar uno de ellos, o bien recibieron del rey un título en blanco para vender. Por medio de este sistema obtuvo el título de marqués de Villar del Águila, Juan Antonio Urrutia Retes, quien lo compró a Gaspar Portocarrero ${ }^{125}$. Del mismo modo, Manuel González de Castañeda se convirtió en marqués de la Villa Alcázar en 1690, tras adquirir esta merced a María Agustina Sarmiento ${ }^{126}$.

118. Cfr. Domínguez Ortiz, A.: La sociedad española en el siglo XVII..., op. cit., vol. I, p. 212.

119. Cfr. SÁnchez Belén, J. A.: La política fiscal en Castilla..., op. cit., p. 308.

120. AHN, Consejos, leg. 4441.

121. AGS, Cámara de Castilla, lib. 37, fol. 363 y 380. Previamente se le había concedido a su padre, Juan Fernández de Córdoba Argote, el título de vizconde de Torres Cabrera. Cfr. Soria Mesa, E.: El cambio inmóvil. Transformaciones y permanencias en una elite de poder (Córdoba, ss. XVI-XIX). Córdoba, 2000, p. 185.

122. Sobre los Chilton Fantoni, vid. Iglesias Rodríguez, J. J.: El árbol de Sinople. Familia y patrimonio entre Andalucía y Toscana en la Edad Moderna. Sevilla, 2008, pp. 72-77. Acerca del linaje Fantoni veáse además: FANTONI y BenEdi, R.: «Los Fantoni: regidores perpetuos de Cádiz (15961835)», Hidalguia, Volumen extraordinario conmemorativo del XXV aniversario de la fundación. Madrid, 1978, pp. 231-249.

123. Vid. Iglesias Rodríguez, J. J.: El árbol de Sinople..., op. cit., p. 73.

124. AHN, Consejos, leg. 9270. Para satisfacer los referidos 22.000 ducados, le fue preciso pedir facultad real para enajenar algunos de sus bienes vinculados, de entre los cuales vendió una regiduría en Cádiz a Rodrigo Caballero Yáñez (AGS, Cámara de Castilla, lib. 40, fol. 64 v).

125. AGS, Secretaría y Superintendencia de Hacienda, leg. 146-1.

126. Este título se concedió en 1658 a María Agustina Sarmiento, dama de la reina Mariana de Austria, para que recayera en su primogénito fruto del matrimonio con el conde de Aguilar. El título 
Otro modo de hacerse con un título nobiliario fue a través de los virreyes de Indias, que fueron comisionados en algunas ocasiones para enajenar estos honores en América, territorios donde convergía una mayor disponibilidad de capital y una gran ambición social ${ }^{127}$. Durante los últimos veinte años del reinado de Carlos II se autorizó tanto al duque de la Palata, virrey de Perú ${ }^{128}$, como al conde de Galve, virrey de Nueva España ${ }^{129}$, para vender un número determinado de títulos y obtener así dinero extra para determinados gastos de la monarquía. De forma similar, para devolver a Francisco Bernaldo de Quirós unas cantidades que se le estaban debiendo ${ }^{130}$, concretamente 26.881 pesos del tiempo que había servido en Roma, la Corona encomendó a los virreyes americanos la tarea de beneficiar un total de cinco títulos de Castilla por valor de 6.000 pesos cada uno. Tres de ellos fueron enajenados por medio del conde de Galve, virrey de Nueva España, siendo los adquirientes Francisco Javier Vasconcelos, marqués de Monserrate ${ }^{131}$, Bartolomé Ortiz de Casqueta, marqués de Altamira ${ }^{132}$, y Juan Bravo Acuña de Medrano, conde de Santa Rosa ${ }^{133}$. Los otros dos serían vendidos en Perú a través del conde de la Monclova, recayendo uno de ellos en Manuel Ponce, vecino de Quito, quien pagó por el título 11.741 pesos $^{134}$.

$\mathrm{Al}$ igual que los virreyes, los presidentes del Consejo de Indias también fueron comisionados para la venta de estas mercedes. Tal es el caso del marqués de los Vélez, quien estuvo al cargo de la operación venal que tuvo lugar a finales del

no llegó a ser ocupado, por lo que en atención a los cortos medios de María Agustina, por decreto de 17 de octubre de 1689, se le concedió facultad para venderlo. El comprador sería el referido Manuel González de Castañeda, caballero de la orden de Calatrava y General de la Artillería. AHN, Consejos, leg. 8975 , exp. 23 y exp. 28.

127. Sobre los títulos nobiliarios enajenados en Indias, véase, entre otros, el trabajo de MaruRI Villanueva, R.: «Poder con poder se paga: títulos nobiliarios beneficiados en Indias (1681-1821)», Revista de Indias, 69, 246 (2009), pp. 207-239.

128. La primera vez fue en 1681, cuando se le mandó beneficiar cuatro títulos de Castilla por valor de 30.000 pesos de a ocho reales cada uno. Vid. De Las Heras Borrero, F. M.: «Compra de títulos nobiliarios en Perú durante el reinado de Carlos II», Hidalguía, 154-155 (1979), p. 397 y ss. En 1685, se le volvería a encargar al virrey del Perú la venta de otros cuatro títulos de Castilla. Vid. Konetzke, R.: Colección de documentos para la historia de la formación social de Hispanoamérica, 1493-1810. Madrid, 1953, p. 778.

129. Fue hacia 1690 cuando se le encomendó al conde de Galve, virrey de Nueva España, vender dos títulos de Castilla en blanco con el fin de que los enajenase «en personas de calidad y lustre» por la mayor cantidad posible. AGI, México, leg. 601.

130. Francisco Bernaldo de Quirós fue caballero de la orden de Santiago, consejero del Consejo de Órdenes Militares, y en el momento de la venta de los títulos estaba sirviendo como enviado extraordinario en Holanda. AGI, Títulos de Castilla, leg. 11, 5.

131. AHN, Consejos, leg. 8975, exp. 96.

132. AGI, Títulos de Castilla, leg. 11, 5 .

133. AGI, Títulos de Castilla, leg. 11, 5. Juan Bravo Acuña gozaba de una gran fortuna merced al ejercicio de la minería. Cfr. LANGUE, F.: «Del minero rico a la nobleza: el papel de la frontera zacatecana en la formación de una elite económica y social», Anuario de Estudios Americanos, 44 (1987), p. 184.

134. AGI, Indiferente General, leg. 511, 20. 
siglo XVII a través de dicho Consejo ${ }^{135}$. El objetivo de esta operación fue conseguir medios con los que financiar la guerra de Cataluña -fin que justificaba las ventasy otros gastos específicos como los derivados de las Casas Reales ${ }^{136}$. Entre los efectos enajenados por el marqués hubo títulos nobiliarios, como el de conde de Miravalle ${ }^{137}$, adquirido en 1690 por Alonso Dávalos Bracamonte tras desembolsar 10.000 escudos $^{138}$. En 1697, Pedro Núñez de Prado, conde de Adanero y también presidente del Consejo de Indias, estuvo igualmente al frente del beneficio de una serie de efectos que debían correr por su mano, ${ }^{139}$ entre los cuales estuvo el título que vendió a Pedro Cortés Monroy, quien en 1697 pagó 120.000 reales por convertirse en marqués de Piedra Blanca de Huana ${ }^{140}$, y por la prorrogación por dos vidas de la encomienda de Guana en el Reino de Chile ${ }^{141}$.

\section{Conclusiones}

El siglo Xvir supuso un cambio significativo para el estamento nobiliario, y más concretamente, para su sector más elevado, la nobleza titulada, grupo que se amplió de forma considerable-fundamentalmente a partir del último cuarto de siglo-merced al ingreso de nuevos miembros, muchos de los cuales habían pagado por sus títulos nobiliarios. Todavía con Felipe IV se mantuvo como principal vía de acceso a los títulos nobiliarios aquella que estaba fundamentada en la sangre y el mérito, siendo numerosos los individuos que, procedentes de las principales familias nobiliarias del reino, lograron acumular en su persona o Casa varios títulos de condes, marqueses, duques, e incluso de Grandes de España. No obstante, durante el reinado de su sucesor, Carlos II, el panorama cambió de forma significativa a partir de la nueva política de creación de títulos nobiliarios, pues la nobleza titulada experimentó un crecimiento sin precedentes, provocado fundamentalmente por la venta masiva de estas mercedes que coincidió además con un incremento de la enajenación de empleos tanto en la administración como en el ejército, y con un aumento de la venalidad en América. Este selecto grupo, tradicionalmente impenetrable para quienes no gozaban de sangre noble, se abrió entonces a nuevos miembros que accedían a la categoría de condes o marqueses merced a los servicios desempeñados en el gobierno de la monarquía, pero también a los servicios pecuniarios prestados a la Corona,

135. SANZ TAPIA, Á.: ¿Corrupción o necesidad?..., op. cit., pp. 67, 68, 73 y 74.

136. Andújar Castillo, F.: Necesidad y venalidad. España e Indias, 1704-1711. Madrid, 2008, pp. 34-35; también p. 251.

137. AHN, Consejos, leg. 8975, exp. 27.

138. AGI, Contaduría, leg. 157 y AGI, Contaduría, leg. 155.

139. AGI, Contaduría, leg. 163.

140. AGS, Cámara de Castilla, lib. 41, Fol. 426.

141. AGI, Contaduría, leg. 163. 
«mérito» este, el del dinero, que funcionó como otro cualquiera -aunque tuvo distinta consideración social-y que permitió burlar, sobre todo en coyunturas de necesidad económica para la monarquía, cualquier filtro de control sobre el origen social.

La posibilidad de adquirir un título nobiliario a través de las diferentes vías expuestas, comportó, no solo un fuerte incremento de estos honores, sino también una profunda renovación del perfil de las elites que hasta entonces habían configurado la nobleza titulada, pues hubo determinados sectores, pertenecientes normalmente a las oligarquías locales y municipales, o bien, a las elites económicas emergentes, como financieros, terratenientes o comerciantes, que vieron en la compra de estas mercedes la mejor oportunidad para instalarse en la cúspide del estamento nobiliario sin mucha dificultad. Por lo general pertenecían a familias insertas en procesos de ascenso social desde generaciones atrás. Era frecuente que antes de titular hubieran accedido a cargos políticos o municipales que reportaban privilegio y distinción, o que hubieran logrado algún grado militar que comportara nobleza. Habitual fue además que adquirieran, de forma previa, tierras para fundar mayorazgos, o que compraran señoríos sobre los que situar el título nobiliario. Asimismo, la conquista de la hidalguía -mediante la compra de un privilegio, el inicio de un pleito en alguna de las dos Chancillerías, o el empadronamiento como hidalgos en lugares ajenos a los de residencia- junto con la obtención de un hábito de las Órdenes Militares, muestra irrefutable, en apariencia, de calidad y nobleza, situarían a los agraciados a las puertas de la nobleza titulada.

Las numerosas ventas producidas a finales del siglo xvi beneficiaron a algunos pero también perjudicaron a otros, en este caso, a las Casas nobiliarias más antiguas y prestigiosas, quienes no tardaron en manifestar su descontento ante la llegada masiva de individuos que, carentes de más calidad o mérito que el dinero, lograban acceder sin ningún tipo de traba a lo que había sido un grupo distinguido e inaccesible. No obstante, los intereses de la Corona iban por otros derroteros, pues su objetivo, lejos de ser el de preservar la «pureza» sanguínea de este conjunto o el hermetismo en que había vivido hasta entonces, no fue otro que recaudar medios económicos con que financiar guerras y gastos cortesanos, así como integrar a estas nuevas «elites del dinero» en el sistema de la monarquía a través de su entrada en la nobleza titulada. De este modo, el monarca se atraía para sí el apoyo de grupos que no solo reforzarían a este estrato nobiliario, sino que también le serían muy útiles merced a su poder económico.

La dinámica implantada durante el reinado de Carlos II en cuanto a la creación de títulos nobiliarios, así como las distintas sendas de acceso - venales y no venales-a los mismos, si bien supusieron una evidente ruptura con los reinados precedentes, se mantendrían prácticamente inmutables a lo largo de la siguiente centuria. 